RESEARCH REPORT

\title{
Influence of change in psychosocial work characteristics on sickness absence: the Whitehall II study
}

\author{
Jenny Head, Mika Kivimäki, Pekka Martikainen, Jussi Vahtera, Jane E Ferrie, Michael G Marmot
}

J Epidemiol Community Health 2006;60:55-61. doi: 10.1136/jech.2005.038752

See end of article for authors' affiliations

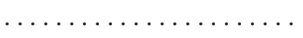

Correspondence to: Jenny Head, Department of Epidemiology and Public Health, University College London, London WCIE 6BT, UK; j.head@ ucl.ac.uk

Accepted for publication 21 August 2005

\begin{abstract}
Objectives: To study the influence of change in self perceived psychosocial work characteristics on subsequent rates of sickness absence.

Methods: Prospective cohort study of British civil service employees. Job control, job demands, and work social supports were measured in 1985/88 and in 1991/93. Analyses included 3817 British civil servants with sickness absence records at baseline (1985-89) and for two follow up periods, early (1994-95) and later follow up (1996-98).

Results: Change in work characteristics predicted subsequent incidence of long spells of sickness absence (>7 days) in the early follow up period after adjustment for covariates including baseline work characteristics, health status, and sickness absence. Adjusted rate ratios were 1.23 (95\% Cl 1.03 to 1.46 ) for decreased compared with stable decision latitude; $1.17(95 \% \mathrm{Cl} 1.01$ to 1.36$)$ for increased compared with stable job demands and 0.79 (95\% $\mathrm{Cl} 0.67$ to 0.93 ) for increased compared with stable work social support. These associations were also seen in a sub-sample who did not change employment grade. In the later follow up period, associations between work change and long spells of sickness absence were similar for decision latitude, less pronounced for job demands, and no longer apparent for social supports. Changes in work characteristics were not associated with subsequent short spells of sickness absence ( $\leqslant 7$ days).

Conclusions: Adverse changes in the psychosocial work environment may lead to increased rates of sickness absence. These findings suggest that workplace interventions to improve psychosocial working conditions may reduce levels of sickness absence.
\end{abstract}

F indings from prospective studies show that stressful working conditions, such as low decision latitude, high job demands, and low work social supports, are related to subsequent ill health including psychiatric morbidity, poor health functioning, ${ }^{2}{ }^{3}$ sickness absence, ${ }^{4-6}$ and coronary heart disease. ${ }^{7-9}$ As a result, a stressful working environment is now recognised as a workplace hazard and policies are being introduced to improve psychosocial working conditions. For example, in 2004 the UK Health and Safety Executive introduced management standards for work related stress covering domains that included demands, control, and work supports. ${ }^{10}$

It has been suggested that a potential benefit for employers who manage to improve psychosocial working conditions is reduced levels of sickness absence. However, the few previous studies that have examined the impact of change in psychosocial working conditions on subsequent sickness absence have been limited to a context of organisational downsizing. ${ }^{11}{ }^{12}$ Thus, research is still needed to determine the short and long term influences of changes in psychosocial work environment that occur in less exceptional settings.

The Whitehall II study provides an opportunity to study the impact of change in work characteristics on health as this London based cohort of civil servants was recruited during a period of stable employment (1985-88) but subsequently there was a period during which some sections of the civil service underwent restructuring, including the application of market forces. This was reflected in changes in self report work characteristics between phase 1 of the study (1985-89) and phase 3 (1991-93) as job demands increased, work social supports decreased, and decision latitude improved. ${ }^{5}$ However, these changes did not affect participants equally and so we were able to divide the cohort into those who experienced adverse or beneficial change and compare sickness absence rates in these groups with rates for those whose work environment had remained unchanged. Previous findings from the Whitehall II study have shown an association between levels of work characteristics and subsequent sickness absence. ${ }^{4}$ The aim of this paper is to examine the influence of changes in psychosocial working conditions on subsequent sickness absence levels in both an early follow up period (1994-95) and a later period (199698 ). We analyse short ( $\leqslant 7$ days) and long ( $>7$ days) spells of sickness absence separately as long spells of sickness absence have been found to be stronger predictors of mortality and other objective measures of physical illnesses and medical conditions. ${ }^{13-15}$

\section{METHODS \\ Participants}

Non-industrial civil servants aged 35-55 years working in the London offices of 20 departments were invited to participate in the Whitehall II study. ${ }^{16}$ Between 1985 and 1988, participants attended a screening examination and completed a self report questionnaire (phase 1). Altogether 10308 civil servants (6895 men and 3413 women) were examined giving an overall response rate of $73 \%$. A postal questionnaire was administered in 1989 (phase 2) and participants took part in a further screening examination in 1991-1993 (phase 3). The participation rate at phase 3 was $83 \%$. The average follow up between phase 1 and phase 3 was 5.3 years. Ethical approval for the Whitehall II study was obtained from the University College London Medical School committee on the ethics of human research.

\section{Work characteristics}

Self completion questions were based on the Karasek and Theorell job content instrument. ${ }^{17}$ Decision latitude (15 
items; Cronbach's $\alpha=0.84$ ), psychological job demands (4 items, Cronbach's $\alpha=0.67$ ), and work social supports (6 items; Cronbach's $\alpha=0.79$ ) were measured at phase 1 (198585 ) and phase 3 (1991-1993). Total scores were expressed as a percentage of the maximum for each scale so that scores ranged from 0 to 100 .

At phase 3, repeat measurements of work characteristics were collected about one month later for a subsample of 267 participants. The within subject standard deviation from this test-retest data gives an estimate of measurement error and was 7.1, 11.7, and 11.2 for decision latitude, job demand, and work social supports respectively.

Change in work characteristic scores from phases 1 to 3 were computed and participants were classified into one of three groups "stable", "decrease" (decrease >10 scale points), or "increase" (increase $>10$ scale points). Change in job strain (high demands in combination with low decision latitude) was also examined. At each phase, participants were classified into three categories: high job strain if they reported both high job demands and low decision latitude (classified as above and below the median score respectively), low job strain if they reported both low job demands and high decision latitude, and medium job strain otherwise. Change in job strain between phase 1 and 3 was categorised as: "stable", "decrease", or "increase".

\section{Sickness absence}

Computerised sickness absence records were obtained from civil service pay centres for $9179(89 \%)$ of the 10308 participants. For absences of seven calendar days or less, civil servants were able to complete their own certificate and explain the absence. For absences longer than seven days, a medical certificate was required. Sickness absence records were checked and any overlapping or consecutive spells of sickness absence were merged after taking account of weekends and public holidays. For each employee, we calculated the number of long spells ( $>7$ days) and the number of short spells ( $1-7$ days) for two periods subsequent to the measurement of work change, an early follow up (1994-95) and a later follow up (1996-1998). We also calculated measures for a baseline period of sickness absence (1985-1989) expressed as rates for each employee: number of short spells per year, number of long spells per year, and number of days absent per year.

\section{Other covariates}

Employment grade was obtained by asking participants for their civil service grade title. The Civil Service identifies 12 non-industrial grade levels on the basis of salary. For analysis purposes, these grade levels were grouped into six categories ranging from top administrative grades to clerical/office support grades. Job mobility was defined as change in employment grade between phases 1 and 3. Health and health behaviour measures at baseline included presence of longstanding illness, minor psychiatric morbidity (score $>4$ on the 30 item general health questionnaire), presence of recurring health problems in the previous year, frequency of alcohol consumption in the past year, and smoking status. Body mass index was computed from recordings of height and weight at screening. ${ }^{16}$

\section{Statistical analysis}

We fitted Poisson regression models to study the association of change in psychosocial work characteristics with incidence of both short and long spells of sickness absence. For short spells, there was considerable residual variation in excess of the Poisson distribution so standard errors and confidence intervals were inflated to take account of this overdispersion. ${ }^{18}$ We tested whether associations differed by sex or employment grade by including interaction terms. No significant interactions were detected so results are presented for men and women combined. As job mobility or change in income could be potential confounding factors, we repeated analyses for the subgroup who did not change employment grade. We also examined whether presence of longstanding illness at baseline or baseline long spells of sickness absence (none compared with any long spells) moderated the association between work change and subsequent spells of sickness absence by fitting models including interaction terms between these variables and change in working conditions. The statistical significance of interactions was tested by comparing the goodness of fit of models with and without the interaction terms. All analyses were performed using the SAS program version 8.02.

\section{RESULTS}

Information on baseline sickness absence, decision latitude, job demands, and work social supports at both phases 1 and 3 was available for 6637 participants. Of these, 4018 participants were still working in the civil service and had

Table 1 Psychosocial work characteristics at phase 1 (1985-88) and phase 3 (1991-93) and change in psychosocial work characteristics between phases 1 and 3

\begin{tabular}{|c|c|c|c|}
\hline & Decision latitude & Job demands & Work social supports \\
\hline \multicolumn{4}{|l|}{ All participants $(n=3817)$} \\
\hline Mean score (SD) at phase 1 & $65.8(15.8)$ & $58.1(20.3)$ & $76.0(18.3)$ \\
\hline Mean score (SD) at phase 3 & $68.3(14.9)$ & $61.7(18.9)$ & $75.8(17.5)$ \\
\hline Mean change* $(S D)$ & $2.5(11.9)$ & $3.6(19.6)$ & $-0.2(19.7)$ \\
\hline p valuet & $p<0.0001$ & $p<0.0001$ & $p=0.45$ \\
\hline Number (\%) with increased score & $926(24)$ & $1196(31)$ & $1113(29)$ \\
\hline Number (\%) with stable score $\neq$ & $2407(63)$ & $1868(49)$ & $1472(39)$ \\
\hline Number (\%) with decreased score & 484 (13) & $753(20)$ & $1232(32)$ \\
\hline Stable employment grade ( $n=2746$ ) & & & \\
\hline Mean score (SD) at phase 1 & 64.7 (16.2) & $57.3(20.6)$ & 75.5 (18.7) \\
\hline Mean score (SD) at phase 3 & $66.3(15.3)$ & $60.1(19.1)$ & $75.7(17.5)$ \\
\hline Mean change* $(S D)$ & $1.6(11.8)$ & $2.9(19.5)$ & $0.2(20.1)$ \\
\hline p valuet & $p<0.0001$ & $p<0.0001$ & $p=0.63$ \\
\hline Number (\%) with increased score & $603(22)$ & $828(30)$ & $812(30)$ \\
\hline Number $(\%)$ with stable score & $1758(64)$ & $1353(49)$ & $1066(39)$ \\
\hline Number (\%) with decreased score & 385 (14) & $565(21)$ & $868(32)$ \\
\hline
\end{tabular}

*Change $=$ phase 3 - phase 1 score. $†$ Paired $t$ test for change in work score between phases 1 and $3 . \ddagger^{\prime \prime S t a b l e "}$ defined as change $\leqslant 10$ scale points. Increase and decrease defined as change $>10$ scale points. 
Table 2 Rate ratios (95\% Cl) for long spells of sickness absence ( $>7$ days) in early follow up (1994-95) by change in psychosocial work characteristics between phase 1 (1985-88) and phase 3 (1991-93)

\begin{tabular}{|c|c|c|c|c|c|}
\hline & \multirow[b]{2}{*}{ Rate } & \multicolumn{3}{|l|}{ All participants ( $n=3817$ ) } & \multirow{2}{*}{$\begin{array}{l}\text { Stable employment grade } \\
(\mathrm{n}=2746)\end{array}$} \\
\hline & & $\begin{array}{l}\text { Adjusted for age, sex, } \\
\text { employment grade }\end{array}$ & $\begin{array}{l}\text { + baseline work } \\
\text { characteristics* }\end{array}$ & All adjustments $\dagger$ & \\
\hline \multicolumn{6}{|l|}{ Decision latitude } \\
\hline Increase & 16.1 & $1.02(0.88$ to 1.18$)$ & 0.97 (0.83 to 1.13 ) & 1.02 (0.87 to 1.19$)$ & $1.00(0.83$ to 1.20$)$ \\
\hline Stable & 13.4 & & & & \\
\hline Decrease & 20.1 & 1.31 (1.10 to 1.55$)$ & $1.34(1.13$ to 1.59$)$ & $1.23(1.03$ to 1.46$)$ & $1.17(0.96$ to 1.42$)$ \\
\hline Test for linear trend $\neq$ & & $p=0.05$ & $p=0.006$ & $p=0.05$ & $p=0.11$ \\
\hline \multicolumn{6}{|l|}{ Job demands } \\
\hline Increase & 16.7 & $1.10(0.96$ to 1.27$)$ & $1.21(1.04$ to 1.40$)$ & $1.17(1.01$ to 1.36$)$ & 1.30 (1.09 to 1.54$)$ \\
\hline Stable & 14.1 & & 1 & & 1 \\
\hline Decrease & 14.1 & $0.97(0.82$ to 1.15$)$ & $0.89(0.75$ to 1.06$)$ & 0.85 (0.71 to 1.01$)$ & $0.90(0.73$ to 1.11$)$ \\
\hline \multicolumn{4}{|l|}{ Work social supports } & $p=0.005$ & $p=0.001$ \\
\hline Increase & 14.8 & $0.87(0.75$ to 1.01$)$ & $0.80(0.68$ to 0.95$)$ & $0.79(0.67$ to 0.93$)$ & $0.78(0.64$ to 0.94$)$ \\
\hline Stable & 15.5 & & 1 & & \\
\hline Decrease & 14.3 & $0.94(0.81$ to 1.09$)$ & $0.96(0.83$ to 1.11$)$ & $0.87(0.75$ to 1.01$)$ & 0.90 (0.76 to 1.07$)$ \\
\hline Test for linear trend $\ddagger$ & & $p=0.10$ & $p=0.003$ & $p=0.10$ & $p=0.06$ \\
\hline
\end{tabular}

sickness absence data for the period 1994-95 and were therefore eligible for this analysis. Information on some baseline covariates was missing for 201 (5\%) of this group. Therefore, this paper includes the 3817 participants (1048 women, 2769 men) with measures of psychosocial work characteristics at phases 1 and 3, sickness absence data in 1994-95 and complete data on baseline covariates.

Table 1 shows levels of work characteristics at phase 1 and phase 3 and change in work characteristics between phase 1 and 3. A decrease in decision latitude and social support scores would be considered an adverse change whereas a decrease in job demands score would be considered a beneficial change. On average, there was a significant adverse change in job demands whereas decision latitude tended to improve. Although average social support scores were similar at the two phases, there were individual changes between phases 1 and 3 so that only $39 \%$ were classified as having stable scores. For all three work characteristics, the standard deviation for change between phases 1 and 3 was about 1.7 greater than the within subject standard deviation estimated from short term test-retest data indicating that changes were greater than might be expected from measurement error alone. Similar patterns of change in work characteristics were seen for the 2746 participants whose employment grade did not change.

\section{Long spells of sickness absence (1994-1995)}

Table 2 shows the association of change in work characteristics with subsequent long spells of sickness absence in the early follow up period (1994-1995). Results for three models are presented, the first adjusting for age, grade, and sex only, the second with an additional adjustment for baseline work characteristics, and the third additionally adjusting for job mobility, pre-existing baseline health, baseline rates of sickness absence and other predictors of sickness absence (alcohol consumption, smoking habits, and body mass index). After adjustment for age, grade, and sex, adverse change in decision latitude was associated with increased rates of long spells of sickness absence (rate ratio 1.31). This association was not explained by baseline levels of work characteristics. The association was reduced but still significant in the fully adjusted model (rate ratio 1.23).

Change in job demands was not significantly related to long spells of sickness absence in the age-grade-sex adjusted model. However, after taking account of baseline work characteristics, those with adverse changes in job demands had an increased risk of long spells of sickness absence (rate ratio 1.21). This association was slightly reduced but still significant in the fully adjusted model (rate ratio 1.17). A decrease in job demands was associated with reduced risk of long spells of sickness absence.

Table 3 Rate ratios* (95\% Cl) for long spells of sickness absence (>7 days) in later follow up (1996-1998) by change in psychosocial work characteristics between phase 1 (1985$88)$ and phase 3 (1991-93)

\begin{tabular}{|c|c|c|c|}
\hline & Increase & Stable & Decrease \\
\hline \multicolumn{4}{|c|}{ All participants ( $n=3052)$} \\
\hline Decision latitude & 1.15 (0.99 to 1.34$)$ & 1 & 1.21 (1.02 to 1.45$)$ \\
\hline Job demands & 1.09 (0.94 to 1.27$)$ & 1 & 1.13 (0.95 to 1.33 ) \\
\hline Work social supports & $1.01(0.86$ to 1.19$)$ & 1 & 1.05 (0.91 to 1.22$)$ \\
\hline \multicolumn{4}{|c|}{ Stable employment grade $(n=2130$ ) } \\
\hline Decision latitude & $1.07(0.90$ to 1.29$)$ & 1 & 1.11 (0.91 to 1.35$)$ \\
\hline Job demands & $1.20(1.01$ to 1.42$)$ & 1 & $1.16(0.95$ to 1.40$)$ \\
\hline Work social supports & $0.95(0.79$ to 1.14$)$ & 1 & $1.03(0.86$ to 1.22$)$ \\
\hline
\end{tabular}

*Adjusted for sex, baseline age, employment grade, baseline work characteristics (decision latitude, job demands, work social supports), change in employment grade between phases 1 and 3 , baseline health (longstanding illness, health problems in past year, GHQ caseness), frequency of alcohol consumption in past year, smoking habits, body mass index, baseline sickness absence (rate of short spells per year 1985-89, rate of long spells per year 1985-89, rate of days per year 1985-89). 
Table 4 Rate ratios (95\% Cl) for short spells of sickness absence ( $\leqslant 7$ days) in early follow up (1994-95) by change in psychosocial work characteristics between phase 1 (1985-88) and phase 3 (1991-93)

\begin{tabular}{|c|c|c|c|c|c|}
\hline & \multirow[b]{2}{*}{ Rate } & \multicolumn{3}{|l|}{ All participants $(n=3817)$} & \multirow{2}{*}{$\begin{array}{l}\text { Stable employment grade } \\
\text { ( } \mathrm{n}=2746)\end{array}$} \\
\hline & & $\begin{array}{l}\text { Adjusted for age, sex, } \\
\text { employment grade }\end{array}$ & $\begin{array}{l}\text { + baseline work } \\
\text { characteristics }\end{array}$ & All adjustments $\dagger$ & \\
\hline \multicolumn{6}{|l|}{ Decision latitude } \\
\hline Increase & 125.3 & $0.99(0.88$ to 1.18$)$ & 0.91 (0.82 to 1.02 ) & 0.95 (0.85 to 1.07$)$ & 0.91 (0.80 to 1.05$)$ \\
\hline Stable & 109.6 & & & & \\
\hline Decrease & 136.9 & 1.09 (0.96 to 1.24$)$ & $1.13(1.00$ to 1.29$)$ & 1.08 (0.94 to 1.23 ) & $1.08(0.93$ to 1.25$)$ \\
\hline \multicolumn{2}{|l|}{$\begin{array}{l}\text { Test for linear trendf } \\
\text { Job demands }\end{array}$} & $p=0.46$ & $p=0.01$ & $p=0.15$ & $p=0.16$ \\
\hline Increase & 124.4 & 1.03 (0.94 to 1.14 ) & 1.01 (0.90 to 1.12 ) & 1.00 (0.90 to 1.11$)$ & $0.99(0.87$ to 1.12$)$ \\
\hline Stable & 112.0 & & & & \\
\hline Decrease & 116.3 & 0.99 (0.88 to 1.12 ) & $1.02(0.90$ to 1.16$)$ & $1.02(0.90$ to 1.16$)$ & 0.99 (0.86 to 1.14$)$ \\
\hline \multirow{2}{*}{\multicolumn{6}{|c|}{$\begin{array}{l}\text { Test for linear trendf } \\
\text { Work social supports }\end{array}$}} \\
\hline & & & & & \\
\hline Increase & 116.4 & 0.95 (0.85 to 1.05 ) & 0.90 (0.80 to 1.01$)$ & 0.91 (0.81 to 1.02 ) & 0.92 (0.80 to 1.05 ) \\
\hline Stable & 116.3 & & & & \\
\hline Decrease & 117.5 & $1.04(0.93$ to 1.15$)$ & 1.05 (0.95 to 1.17$)$ & 1.01 (0.91 to 1.12 ) & 1.00 (0.88 to 1.13 ) \\
\hline Test for linear trend $\neq$ & & $p=0.17$ & $p=0.01$ & $p=0.24$ & $p=0.34$ \\
\hline \multicolumn{6}{|c|}{$\begin{array}{l}\text { Rate of short spells per } 100 \text { person years. *Decision latitude, job demands, work social supports. †Adjusted for sex, baseline age, employment grade, baseline } \\
\text { work characteristics (decision latitude, job demands, work social supports), change in employment grade between phases } 1 \text { and } 3 \text {, baseline health (longstanding } \\
\text { illness, health problems in past year, GHQ caseness), frequency of alcohol consumption in past year, smoking habits, body mass index, baseline sickness absence } \\
\text { (rate of short spells per year 1985-89, rate of long spells per year 1985-89, rate of days per year 1985-89). †Test for linear trend in continuous work change } \\
\text { score. }\end{array}$} \\
\hline
\end{tabular}

Although there was no clear linear trend for work social supports, beneficial changes in work social supports predicted reduced rates of long spells of sickness absence after adjustment for all covariates (rate ratio 0.79).

The above analyses were replicated for the subgroup whose employment grade did not change to discount job mobility (and corresponding changes in status and income) as a possible explanation for the observed associations (table 2). Similar patterns of results were seen with adverse changes in decision latitude or job demands predicting higher rates of long spells of sickness absence and beneficial changes in work social supports predicting lower rates of long spells of sickness absence. Tests of interaction for differences by sex or employment grade in the influence of work change on sickness absence were all non-significant. Less than $5 \%$ of the sample had spells in total of 90 or more days and excluding these people with very long absences from the analysis had little effect on our findings.

The Karasek job strain model suggests that high job demands will have the greatest adverse effect on health in those with low decision latitude. Increase in job strain was a significant predictor of long spells of sickness absence (rate ratio 1.24). However, this finding may reflect the combined additive effect of adverse changes in job demands and decision latitude.

We examined whether the association of work change with subsequent long spells of sickness absence differed according to pre-existing baseline ill health. The association of change in decision latitude with long spells of sickness absence differed according to presence or absence of longstanding illness at baseline ( $p$ value for interaction $<0.001$ ). Adverse change in decision latitude was a stronger predictor of long spells of sickness absence among those reporting a baseline longstanding illness (adjusted rate ratio 1.38). Interaction terms for baseline ill health by change in job demands and by change in work social support were not significant.

\section{Long spells of sickness absence (1996-1998)}

As change in work characteristics may also have long term effects, we examined long spells of sickness absence for a later period (1996-98). A total of 3052 participants were included in this analysis and table 3 gives results from the

\section{What this paper adds}

- Change in psychosocial characteristics of the work environment is associated with subsequent long spells of sickness absence

- Adverse changes in decision latitude increase risk of long spells of sickness absence

- Increasing levels of job demands relate to risk of long spells of sickness absence

- Improvements in work social supports reduce risk of long spells of sickness absence

model including adjustments for all covariates. A similar effect size was obtained for change in decision latitude with a rate ratio of 1.21 for decreased decision latitude (compared with 1.23 in the early period). The effect size for job demands was slightly reduced in the later period with a rate ratio of 1.09 for increased job demands in the later period (compared with 1.17 in the early period). However, change in work social support was not significantly associated with long spells of sickness absence in the later period (rate ratio of 1.01 for improved social support compared with 0.79 in the early period).

\section{Short spells of sickness absence}

Table 4 presents the association between change in work characteristics and subsequent rates of short spells of sickness absence in the early follow up years (1994-95). Changes in decision latitude, job demands, and work supports were not significant predictors of subsequent rates of short spells. Change in job strain was also not significantly related to rates of short spells (rate ratio for adverse change in job strain versus stable job strain: 0.94). Interactions terms for work change by sex, work change by employment grade and work change by baseline ill health were all nonsignificant. Similar non-significant associations were seen for the later follow up period (results not shown). 


\section{Reverse causality}

The possibility of reverse causality was investigated using linear regression with continuous work change scores as the outcome. Baseline rates of short and long spells of sickness absence were not significant predictors of change in decision latitude or work social supports but baseline rates of long spells did predict change in job demands. The increase in job demands was significantly greater among those not taking any long spells at baseline (mean change in job demands 3.0) compared with those taking two or more long spells (mean change in job demands 1.7). This difference became more pronounced after adjustment for other baseline predictors of change in job demands and was not explained by employment grade.

\section{DISCUSSION}

We have shown that improvements in work social supports were associated with a reduced risk of subsequent long spells of sickness absence and that adverse changes in decision latitude and job demands were related to increased risk of taking long spells of sickness absence. These associations remained after adjustment for baseline work characteristics, job mobility, baseline rates of sickness absence, and other predictors of sickness absence. These associations also existed in the sub-sample that did not change employment grade. A strength of this study is that we were able to take advantage of natural changes in working conditions as the study cohort was recruited during a comparatively stable period of employment. Subsequently, there were important changes in the organisation of the British civil service that were reflected in changes in perceived working conditions.

Earlier findings from the Whitehall II study showed clear relations between baseline work characteristics and prospective sickness absence over a five year period. ${ }^{4}$ Employees with high levels of control and high levels of support at work had lower rates of long spells of sickness absence after adjustment for age and employment grade. Among women, high levels of job demands were also associated with increased risk of long spells of sickness absence. Many other prospective studies have also shown a link between a single measurement of psychosocial work conditions and morbidity, but there is less evidence on the relation between change in working conditions and health.

Our findings on change in psychosocial working conditions correspond with a cross sectional Swedish survey that showed an association between a retrospective report of increased job control and lower sickness absence. ${ }^{19}$ These results also accord with previous longitudinal research investigating changes in job control, job demands, and work social supports among Finnish public sector employees during and after a period of economic decline. Adverse changes in the three work dimensions when compared with beneficial changes were associated with a $10 \%-30 \%$ increased risk of sickness absence after adjustment for baseline job characteristics. ${ }^{12}$ In addition, organisational downsizing predicted increased rates of sickness absence ${ }^{11}$ and cardiovascular mortality ${ }^{20}$ and part of the association between downsizing and sickness absence was explained by concomitant changes in job control and job insecurity. ${ }^{21}$ Swedish studies found that both downsizing and workplace expansion were correlated with increased job strain and adverse psychophysiology, but only expansion was associated with

\section{Policy implications}

Workplace interventions to improve psychosocial working conditions may reduce levels of sickness absence increased sickness absence. ${ }^{22-24}$ In contrast with Finnish findings, downsizing was related to reduction of sickness absence spells exceeding 14 days. ${ }^{22}$ The Whitehall II study found increases in minor psychiatric morbidity and consultations with a general practitioner in an 18 month follow up of employees with insecure employment after privatisation. ${ }^{25}$ Some small scale studies have shown that changes in work characteristics are related to blood pressure ${ }^{26}$ and biochemical risk factors. ${ }^{27}$ Decreased job control over a retrospective 10 year period was associated with myocardial infarction in a case-referent study. ${ }^{28}$ Results from workplace intervention studies suggest that interventions aimed at increasing control and support at work had short term effects on reducing sickness absence rates in the 6-12 months after intervention. ${ }^{29-31}$ A Swedish study explored the changes in the work environment and health of employees after an educational programme for managers at an insurance company. Compared with the control group, improved authority over decisions and lowered serum cortisol were detected among subordinates of managers belonging to the intervention group. $^{32}$

It may be that the health effects of working conditions differ in the short and long term. For example, the impact of adverse working conditions on physical illness may become more apparent over a longer period. In contrast, stronger effects in the short term might represent more immediate health effects such as worsening mental health. We examined the association of work change with sickness absence in the period immediately after reported work change (1994/5) and also a later period (1996/8). The effects of change in decision latitude on long spells of sickness absence did not differ in the early and late period. However, the association of changing job demands was less noticeable in the later period and there was no association between changing work social supports and long spells of sickness absence in the later period.

The difference in short and long term associations raises the possibility that early manifestations of health problems might have influenced the psychosocial exposure. It is also possible that sickness absence behaviour leads to changes in work characteristics rather than the reverse. However, in this study there was little support for such reverse causality in general or as an explanation for observed associations between changes in psychosocial environment and sickness absence. In most cases, baseline health and sickness absence did not predict change in working conditions. The exception was that baseline rate of long spells of sickness absence was inversely associated with subsequent increase in job demands. It may be that sickness absence is both a consequence and a cause of change in job demands. For example, not taking long spells may be related to overcommitment to work that leads to increased job demands.

The effects of a changing psychosocial work environment may not be identical for all employees. While baseline ill health and sickness absence patterns did not predict change in decision latitude, presence of longstanding illness at baseline did seem to moderate the association between change in decision latitude and subsequent risk of taking long spells of sickness absence (significant interaction between change in decision latitude and baseline longstanding illness). These findings suggest that employees with a chronic illness are more likely to take sickness absence if their control over working conditions deteriorates. Associations between work change and sickness absence did not differ significantly between men and women.

We have compared separate groups experiencing adverse or beneficial changes with a "stable working conditions" group. We have also investigated the association between continuous work change scores and sickness absence. There 
was a clear dose-response association between change in job demands and risk of long spells of sickness absence. However, this was less clear for decision latitude where an increase was either not associated (early follow up) or associated with an increased risk of long spells of absence (later follow up). For social supports, sickness absence rates in the early follow up were highest in the group classified as having stable social supports.

Changes in decision latitude, job demands and work supports did not significantly predict subsequent rates of short spells of sickness absence. It is possible that the rate of short spells of sickness absence, in contrast with long spells of sickness absence, does not effectively measure adverse change in health. In the Whitehall II study, long spells of sickness absence have been found to be a more powerful predictor of all cause mortality than established self reported health measures and available objective measures of physical illnesses and medical conditions. ${ }^{13}$ Findings from the 10town study have also shown long spells of sickness absence to be strong predictors of early retirement and several specific causes of death. ${ }^{14} 15$

\section{Methodological considerations}

We were able to take account of important predictors of sickness absence including socioeconomic position, job mobility, baseline health status, baseline sickness absence patterns, and baseline health behaviours. An advantage of studying influence of change in working conditions is that this reduces the possibility that any observed associations are spurious as a result of confounding by unobserved stable personal characteristics. Furthermore, we were able to study change in working conditions independent of change in job mobility so that observed associations are not likely to be attributable to residual confounding by income or social status. ${ }^{33}$ Studies based on self report measures of both work exposure and health may overestimate associations if some people report negatively about both work and health. The use of sickness absence record data means that such common method bias can not be an explanation for our findings. Other strengths were the reliable data on sickness absence and employment grade.

A limitation in this study is that change in psychosocial working conditions was based on measures taken on just two occasions both subject to measurement error. For this reason, we chose to include a fairly wide range of work change scores in the "stable work characteristics" group classifying people into the "stable" group if their change scores were less or equal to 10 score points, equivalent to at least one standard deviation in the baseline distribution of work characteristic scores. Another limitation is that the cohort was restricted to white collar workers in government employment so results may not be generalisable to other types of occupation.

In the demand-control model, an increase in demands combined with a reduction of job control would be expected to be particularly deleterious. Our results suggest that there is little additional synergistic effect of simultaneous change in both job demands and decision latitude. However, our cohort may have been underpowered for this test and a larger sample size may be needed to detect multiplicative interaction effects.

\section{CONCLUSION}

Our findings from a well characterised prospective cohort study show that changes in working conditions influence subsequent long spells of sickness absence. This suggests that there may be a causal association. Less is known about the extent to which organisations are capable of implementing favourable changes and the health consequences of such favourable changes in psychosocial working conditions. Thus, there is now a need for large scale studies of workplace interventions to evaluate the impact of improving working conditions. The methodology for randomised studies is challenging so the next step may be to collect data from systematic "natural" experiments, such as may occur as employers begin to implement new public health policies on work related stress.

\section{ACKNOWLEDGEMENTS}

We thank all participating Civil Service departments and their welfare, personnel, and establishment officers; the Council of Civil Service Unions; all participating civil servants in the Whitehall II study; and all members of the Whitehall II study team.

\section{CONTRIBUTORS}

$\mathrm{J}$ Head analysed the data and led the writing of the article. All the authors designed the hypothesis and contributed to writing the paper. MGM is the director of the Whitehall II study.

\section{Authors' affiliations}

J Head, P Martikainen, J E Ferrie, M G Marmot, Department of Epidemiology and Public Health, University College London, UK M Kivimäki, J Vahtera, Finnish Institute of Occupational Health, Helsinki, Finland

P Martikainen, Population Research Unit, Department of Sociology, University of Helsinki, Finland

Funding: the Whitehall II study has been supported by grants from the Medical Research Council; British Heart Foundation; Health and Safety Executive; Department of Health; National Heart Lung and Blood Institute (HL36310), US, NIH: National Institute on Aging (AG13196), US, NIH; Agency for Health Care Policy Research (HSO6516); and the John D and Catherine T MacArthur Foundation Research Networks on Successful Midlife Development and Socio-economic Status and Health. M.K, also working at the University of Helsinki, Finland, and JV were supported by the Academy of Finland (projects 77560, 104891, and 105195) and the Finnish Environment Fund; PM is supported by the Academy of Finland (70631, 48600, and 210752); JEF is supported by the MRC (grant number 47413), and MGM by an MRC Research Professorship.

Conflicts of interest: none.

\section{REFERENCES}

1 Stansfeld SA, Fuhrer R, Head J, et al. Work and psychiatric disorder in the Whitehall II study. J Psychosom Res 1997;43:73-81.

2 Stansfeld S, Bosma H, Hemingway H, et al. Psychosocial work characteristics and social support as predictors of SF-36 functioning: the Whitehall II study. Psychosom Med 1998;60:247-55.

3 Cheng Y, Kawachi I, Coakley EH, et al. Association between psychosocial work characteristics and health functioning in American women: prospective study. BMJ 2000;320:1432-6.

4 North FM, Syme SL, Feeney A, et al. Psychosocial work environment and sickness absence among British civil servants: the Whitehall II study. Am J Public Health 1996;86:332-40.

5 Stansfeld S, Head J, Ferrie J. Short-term disability, sickness absence, and social gradients in the Whitehall II study. International Journal of Law and Psychiatry 1999;22:425-39.

6 Melchior M, Niedhammer I, Berkman LF, et al. Do psychosocial work factors and social relations exert independent effects on sickness absence? A six year prospective study of the GAZEL cohort. J Epidemiol Community Health 2003;57:285-93.

7 Bosma H, Peter R, Siegrist J, et al. Two alternative job stress models and the risk of coronary heart disease. Am J Public Health 1998;88:68-74.

8 Kivimäki $M$, Leino-Arjas $P$, Luukkonen $R$, et al. Work stress and risk of cardiovascular mortality: prospective cohort study of industrial employees. BMJ 2002;325:857-60.

9 Kuper H, Marmot M. Job strain, job demands, decision latitude, and the risk of coronary heart disease within the Whitehall II study. J Epidemiol Community Health 2003;57:147-53.

10 Health and Safety Executive. Management standards for work-related stress, 3 Nov 2004. http://www.hse.gov.uk/stress/standards/index.htm (accessed 10 Jun 2005).

11 Vahtera J, Kivimäki M, Pentti J. Effect of organisational downsizing on health of employees. Lancet 1997;350:1124-8.

12 Vahtera J, Kivimäki M, Pentti J, et al. Effect of change in the psychosocial work environment on sickness absence: a seven year follow up of initially healthy employees. J Epidemiol Community Health 2000;54:484-93.

13 Kivimäki M, Head J, Ferrie JE, et al. Sickness absence as a global measure of health: evidence from mortality in the Whitehall II prospective cohort study. BMJ 2003;327:364-8. 
14 Vahtera J, Pentii J, Kivimäki M. Sickness absence as a predictor of mortality among male and female employees. J Epidemiol Community Health 2004;58:321-6.

15 Kivimäki M, Forma P, Wikstrom J, et al. Sickness absence as a risk marker of future disability pension: the 10-town study. J Epidemiol Community Health 2004;58:710-11.

16 Marmot MG, Davey Smith G, Stansfeld SA, et al. Health inequalities among British civil servants: the Whitehall II study. Lancet 1991;337:1387-93.

17 Karasek R, Theorell T. Healthy work: stress, productivity, and the reconstruction of working life. New York: Basic Books, 1990.

18 North F, Syme SL, Feeney A, et al. Explaining socioeconomic differences in sickness absence: the Whitehall II study. BMJ 1993;306:361-6.

19 Karasek R. Lower health risk with increased job control among white collar workers. Journal of Organizational Behavior 1990;1 1:171-85.

20 Vahtera J, Kivimäki M, Pentti J, et al. Organisational downsizing, sickness absence, and mortality: 10-town prospective cohort study. BMJ 2004;328:555.

21 Kivimäki M, Vahtera J, Pentti J, et al. Factors underlying the effect of organisational downsizing on health of employees: longitudinal cohort study. BMJ 2000;320:971-5.

22 Theorell T, Oxenstierna G, Westerlund H, et al. Downsizing of staff is associated with lowered medically certified sick leave in female employees. Occup Environ Med 2003;60:E9.

23 Westerlund $\mathrm{H}$, Ferrie J, Hagberg J, et al. Workplace expansion, long-term sickness absence, and hospital admission. Lancet 2004;363:1193-7.

24 Westerlund $\mathrm{H}$, Theorell T, Alfredsson L. Organizational instability and cardiovascular risk factors in white-collar employees: an analysis of correlates of structural instability of workplace organization on risk factors for coronary heart disease in a sample of 3,904 white collar employees in the Stockholm region. Eur J Public Health 2004; 14:37-42.

25 Ferrie JE, Shipley MJ, Marmot MG, et al. Job insecurity in white-collar workers: toward an explanation of associations with health. J Occup Health Psychol $2001 ; 6: 26-42$

26 Theorell T, Perski A, Akerstedt T, et al. Changes in job strain in relation to changes in physiological state. A longitudinal study. Scand J Work Environ Health 1988;14:189-96.

27 Grossi G, Theorell T, Jurisoo M, et al. Psychophysiological correlates of organizational change and threat of unemployment among police inspectors. Integr Physiol Behav Sci 1999;34:30-42.

28 Theorell T, Tsutumi A, Hallqvist J, et al. Decision latitude, job strain, and myocardial infarction: a study of working men in Stockholm. Am J Public Health 1998;88:382-8.

29 Michie S, Wren B, Williams S. Reducing absenteeism in hospital cleaning staff: pilot of a theory based intervention. Occup Environ Med 2004;61:345-9.

30 Bond FW, Bunce D. Job control mediates change in a work reorganization intervention for stress reduction. J Occup Health Psychol $2001 ; 6: 290-302$.

31 Jackson SE. Participation in decision making as a strategy for reducing jobrelated strain. J Appl Psychol 1983;68:3-19.

32 Theorell T, Emdad R, Arnetz B, et al. Employee effects of an educational program for managers at an insurance company. Psychosom Med 2001;63:724-33.

33 Macleod J, Davey Smith G, Heslop P, et al. Are the effects of psychosocial exposures attributable to confounding? Evidence from a prospective observational study on psychological stress and mortality. J Epidemiol Community Health 2001;55:878-84. 